\title{
An optimization of an inventory model of decaying-lot depleted by declining market demand and extended with discretely variable holding costs
}

\author{
Ankit Prakash Tyagi*
}

D.B.S. (PG) College, Dehradun, UK, India

\begin{tabular}{l}
\hline C H R O N I C L E \\
\hline Article history: \\
Received July 22013 \\
Received in revised format \\
September 72013 \\
Accepted September 152013 \\
Available online \\
September 202013 \\
\hline Keywords: \\
Inventory \\
Deterioration \\
Discretely variable holding cost \\
Shortage \\
Partial backlogging \\
\hline
\end{tabular}
\begin{abstract}
A B S T R A C T
Inventory management is considered as major concerns of every organization. In inventory holding, many steps are taken by managers that result a cost involved in this row. This cost may not be constant in nature during time horizon in which perishable stock is held. To investigate on such a case, this study proposes an optimization of inventory model where items deteriorate in stock conditions. To generalize the decaying conditions based on location of warehouse and conditions of storing, the rate of deterioration follows the Weibull distribution function. The demand of fresh item is declining with time exponentially (because no item can always sustain top place in the list of consumers' choice practically e.g. FMCG). Shortages are allowed and backlogged, partially. Conditions for global optimality and uniqueness of the solutions are derived, separately. The results of some numerical instances are analyzed under various conditions.
\end{abstract}

\section{Introduction}

One of the most important concerns of inventory management is to decide when and how much to order so that the total cost associated with the inventory system can be kept at minimum level. When inventory is decaying in nature, it becomes more important since deterioration cannot be ignored. There are various studies in this direction in continuous modification of inventory model for decaying items by including more and more practical features. Researchers are engaging in analyzing inventory models for deteriorating items such as volatile liquids, medicines, electronic components, fashion goods, fruits, vegetables, etc. An order level inventory model with constant deterioration was first developed by Aggarwal (1978).

Now, the inclusion of deterioration aspect into the inventory concept is incorporated in wide range of considered business environments in contemporary inventory models. Sana (2010) studied optimal * Corresponding author.

E-mail: ankitprakashtyagi88@gmail.com (A.P. Tyagi)

(C) 2014 Growing Science Ltd. All rights reserved. doi: $10.5267 / j$.ijiec.2013.09.005 
selling price and lot size with time varying deterioration and partial backlogging. In this effort, an EOQ model over an infinite time horizon for perishable item where demand is price reliant and partial backorder permitted is discussed. Liao and Huang (2010) developed a deterministic inventory model for deteriorating items with trade credit financing and capacity constraints. They offered an inventory model for optimizing the replenishment cycle time for a single deteriorating item under a permissible delay in payments and constraints on warehouse capacity. Hung (2011) urbanized an inventory model with generalized type demand, deterioration and backorder rates. Bhunia and Shaikh (2011) developed a deterministic model for deteriorating items with displayed inventory level dependent demand rate incorporating marketing decisions with transportation cost. Khanra et al. (2011) offered an EOQ model for a deteriorating item with time-dependent quadratic demand under permissible delay in payment. In this study, a step was taken to analyze an EOQ model for deteriorating item considering quadratic time dependent demand rate and permissible delay in payment.

In various situations of inventory control, demand before ending spell exists and the inventory has mostly consumed through joint effect of the demand and the deterioration. This type of situations laid the foundation of supply out phenomena. Consequently, when supply out state occurs, some clients are willing to wait for backorder and others may wish to buy from supplementary sellers. Many researchers such as Park (1982), Hollier and Mak (1983) and Wee (1995) well thought-out the constant partial backlogging rates during the shortage period in their inventory models. In most inventory systems, the length of the waiting time for the next replenishment would come to a decision whether the backlogging will be accepted or not. Therefore, the backlogging rate is variable and dependent on the waiting time for the next replenishment. Chang and Dye (1999) investigated an EOQ model allowing shortage and partial backlogging. They assumed in their inventory model that the backlogging rate was variable and dependent on the length of the waiting time for the next replenishment. Many researchers modified inventory policies by considering the "time-proportional partial backlogging rate" such as Abad (2000), Papachristos and Skouri (2000), Wang (2002), Papachristos and Skouri (2003), etc.

Teng et al. (2003) then unmitigated the fraction of unsatisfied demand back ordered to any decreasing function of the waiting time up to the next replenishment. Teng and Yang (2004) widespread the partial backlogging EOQ model to allow for time-varying purchase cost. Yang (2005) prepared a comparison among various partial backlogging inventory lot size models for deteriorating stuffs on the basis of maximum profit. Teng et al. (2007) compared two pricing and lot sizing model for deteriorating objects with shortages. Dye et al. (2007) urbanized inventory and pricing strategies for deteriorating items with shortages. Skouri et al. (2011) projected an inventory model with general ramp type demand rate, constant deterioration rate, partial backlogging of unfulfilled demand and conditions of permissible delay in payments. Other related articles on inventory system with partial backlogging and shortages have been performed by Hou (2006), Jaggi et al. (2006, 2012), Patra et al. (2010), Yang et al. (2010), Lin (2012), Taleizadeh et al. $(2011,2012)$, etc.

However, a few number of researchers paid their attention towards generalizing the term of holding cost into the inventory models. Therefore, there are few literatures of inventory controlling phenomena under the aspect of variable holding cost. As alarmed above, most researchers unspecified that holding cost rate per unit time is invariable. However, more sophisticated storeroom facilities and services may be required for holding perishable items if they are kept for longer time. Therefore, in holding of perishable items, the assumption of unvarying holding cost rate is not always apt. Weiss (1982) noted that variable holding costs are suitable when the value of an item decreases the longer it is in stock. Ferguson et al. (2007) indicated that this type of model is suitable for perishable items in which price markdowns or removal of aging product are necessary. Alfares (2007) also assumed an inventory model with discretely variable holding cost. Recently, Mishra and Singh (2011) developed the inventory model for deteriorating items with time dependent linear demand and holding cost. 
To give attention on the concept of variability of the holding cost of decaying item, Tyagi et al. (2012) developed an inventory model for decaying item with power demand pattern and managed first Weibull function for holding cost rate. In that study, the holding cost depends continuously on deterioration cost and storage period, shortages were allowed and partially backlogged inversely with the waiting time for the next replenishment. Therefore, this study has left a clear vacuum for study of the discrete change in the holding cost under considering environment of inventory set-ups. Tripathi (2013) studied an inventory model for time varying demand and constant demand; and time dependent holding cost and constant holding cost for case 1 and case 2 respectively. He considered non-decaying items in his model and give a motivation to study our model for deteriorating items with discrete holding cost.

In result, an Economic Order Quantity (EOQ) inventory model of deteriorating item is considered with continuosly declining market demand. To extend such EOQ model in above mentioned directions, it is assumed that the holding cost rate per unit per unit time is discrete variable with respect to time and the deterioration rate of item is considered as two-parameter Weibull distributive function. Partial backlogging is allowed. The backlogging rate is an exponentially decreasing function of the waiting time for the next replenishment.

In this study, the primary problem is to minimize the average total cost per unit time by optimizing the shortage point per cycle. Separateing for each scenario, we show that minimized objective function is convex and the optimal solution is uniquely determined. Numerical example is proposed to illustrate the model and the solution procedure for each scenario of holding cost. The sensitivity analysis of major parameters is separately performed.

\section{Notations}

The following notations are used throughout the whole chapter

$I(t) \quad$ Inventory level at any time $t, t \geq 0$;

$T \quad$ Constant prescribed scheduling period or cycle length (time units);

$I_{\max } \quad$ Maximum inventory level at the start of a cycle (units);

$S \quad$ Maximum amount of demand backlogged per cycle (units);

$t_{1} \quad$ Duration of inventory cycle when there is positive inventory;

$Q \quad$ Order quantity (units/cycle);

$c_{1} \quad$ Cost of the inventory items $(\$)$;

$c_{2} \quad$ Fixed cost per order (\$/order);

$c_{3} \quad$ Shortage cost per unit back-ordered per unit time (\$/unit/unit time);

$c_{4} \quad$ Opportunity cost due to lost sales (\$/unit).

$\operatorname{ATC}_{i}\left(t_{1}^{*}\right) \quad$ Average total cost per unit time in the i-th scenario, where $i=1,2$.

\section{Assumptions}

In developing the mathematical model of the inventory system, the following assumptions are made:

1. Replenishment rate is infinite;

2. Lead time is negligible;

3. The replenishment quantity and cycle length are constant for each cycle;

4. There is no replacement or repair of deteriorated items during a given cycle;

5. The time to deterioration of the item is Weibull dispersed. So, the rate of deterioration $d(t)=\alpha \beta t^{\beta-1}$, where $\alpha$ and $\beta$ are shape and scale parameters; 
6. The demand rate $R_{1}(t)$ is known and decreases exponentially as $R_{1}(t)=D e^{-\lambda t}$ for $I(t)>0$ and $R_{1}(t)=D$ for $I(t) \leq 0$ where $D(>0)$ is initial demand and $0<\lambda<<1$ is a constant governing the decreasing rate of the demand;

7. Shortages are permitted. Unfulfilled demand is partially backlogged. The backlogging rate $B(t)$ which is a decreasing function of the waiting time $t$ for next replenishment, we here assume that $B(t)=e^{-\delta t}$, where $\delta \geq 0$, and $t$ is the waiting time.

\section{Model Formulations}

As depicted above, the inventory arrangement goes like this: At $t=0$, opening replenishment $Q$ units are made, in which $S$ units are delivered towards backorders, leaving a balance of $I_{\max }$ units in the initial inventory. From $t=0$ to $t=t_{1}$ time units, the inventory level depletes owing to both demand and deterioration. At $t_{1}$, the inventory level is zero. During the time $\left(T-t_{1}\right)$ part of the shortage is backlogged and part of it is lost sales. Only the backlogging items are replaced by the after that replenishment.

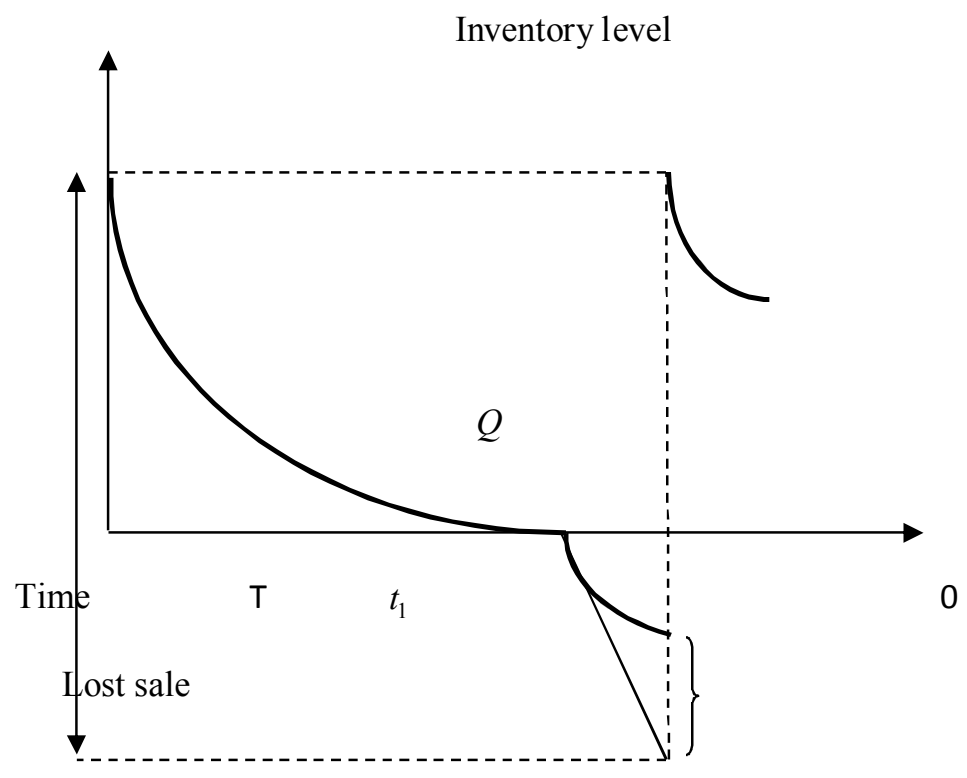

Fig. 1. Inventory system of decaying item for declining market demand

The inventory function with respect to time can be determined by evaluating the differential equations

$$
\begin{aligned}
& \frac{d I(t)}{d t}+d(t) I(t)=-R_{1}(t) \quad 0 \leq t \leq t_{1} \\
& \frac{d I(t)}{d t}=-D B(t) \quad t_{1} \leq t \leq T
\end{aligned}
$$

And with boundary conditions $I(0)=I_{\max }$ and $I\left(t_{1}\right)=0$. The approximate solution of Eq. (1) by neglecting higher order term of $\alpha$ is

$$
I(t)=D\left[\left(t_{1}-t\right)-\lambda\left(\frac{t_{1}^{2}}{2}-\frac{t^{2}}{2}\right)+\frac{\alpha}{\beta+1}\left(t_{1}^{\beta+1}-t^{\beta+1}\right)\right] e^{-\alpha t^{\beta}} ; \quad 0 \leq t \leq t_{1}
$$


Now, again taking the first two terms of the exponential series and neglecting the terms containing $\alpha^{2}$ Eq. (4) becomes

$I(t)=D\left[\left(t_{1}-t\right)-\lambda\left(\frac{t_{1}^{2}}{2}-\frac{t^{2}}{2}\right)+\frac{\alpha}{\beta+1}\left(t_{1}^{\beta+1}-t^{\beta+1}\right)\right]\left(1-\alpha t^{\beta}\right) ; \quad 0 \leq t \leq t_{1}$

So, the maximum inventory level for each cycle can be obtained as

$$
I_{\max }=I(0)=I(t)=D\left[t_{1}-\frac{\lambda t_{1}^{2}}{2}+\frac{\alpha t_{1}^{\beta+1}}{\beta+1}\right]
$$

During the shortage interval $\left[t_{1}, T\right]$, the demand at time $t$ is partially backlogged at the fraction $B(t)=e^{-\delta t}$ Thus, the solution of differential Eq. (2) governing the amount of demand backlogged is as below

$$
I(t)=-\frac{D}{\delta}\left[e^{-\delta(T-t)}-e^{-\delta\left(T-t_{1}\right)}\right], \quad t_{1} \leq t \leq T
$$

with the boundary condition $I\left(t_{1}\right)=0$. Let $t=T$ in Eq. (6), we obtain the maximum amount of demand backlogged per cycle as follows.

$$
S=-I(T)=\frac{D}{\delta}\left[1-e^{-\delta\left(T-t_{1}\right)}\right]
$$

Hence, the order quantity per cycle is given by

$$
Q=I_{\max }+S=D\left(t_{1}-\frac{\lambda t_{1}^{2}}{2}+\frac{\alpha t_{1}^{(1+\beta)}}{(1+\beta)}\right)+\frac{D}{\delta}\left[1-e^{-\delta\left(T-t_{1}\right)}\right]
$$

The order cost per cycle is

$$
O C=c_{2} \text {. }
$$

The deterioration cost per cycle is

$$
D C=\int_{0}^{t_{1}} c_{1} \alpha \beta t^{\beta-1} I(t) d t=c_{1} D \alpha\left[\frac{t_{1}^{(1+\beta)}}{(1+\beta)}-\frac{\lambda t_{1}^{(2+\beta)}}{(2+\beta)}\right] \text {. }
$$

The shortage cost per cycle is

$$
S H=\int_{t_{1}}^{T} c_{3}(-I(t)) d t=\frac{D c_{3}}{\delta}\left[\frac{\left(1-e^{-\delta\left(T-t_{1}\right)}\right)}{\delta}-\left(T-t_{1}\right) e^{-\delta\left(T-t_{1}\right)}\right]
$$

The opportunity cost per cycle is

$$
O P C=\int_{t_{1}}^{T}\left[1-e^{-\delta(T-t)}\right] D d t=c_{4} D\left[\left(T-t_{1}\right)-\frac{\left(1-e^{-\delta\left(T-t_{1}\right)}\right)}{\delta}\right]
$$

\subsection{Holding Cost}

Holding of inventory is a central part of inventory controlling phenomena. When item in collection has a deteriorating nature, it is more to be concerned of such items in stock holding. The owners of inventory have to endow not only for holding such item's units but also invest in handling these items for guardianship in good conditions. We are fascinated by this aspect to demonstrate a mathematical inventory model that can give us a picture which is better and very near to realities of business upbringing. Therefore, here we have understood that the holding cost of inventory is not constant and always depends upon time for which it has held. Now, here holding cost is measured as discretely variable holding cost with storage period. For using these assumptions, we have considered first two 
scenarios for discrete nature of variability of holding cost as retroactively variable holding cost and incrementally variable holding cost as:

Scenario 1: Retroactive holding cost;

Scenario 2: Incremental holding cost;

\subsubsection{Scenario 1: Retroactive Holding Cost}

In this scenario, the unit holding cost per unit time is well thought-out as discrete in nature, and increases as the time in storage increases, $h_{1}<h_{2}<h_{3}<\ldots<h_{n}$, for storage periods 1 through $n$, respectively. A retroactive holding cost implies that the holding cost of the last storage period is applied retroactively to all previous periods in the order cycle. That is, if the cycle length is $\mu_{1}$ or less, the unit holding cost is $h_{1}$ per time period; if the cycle length is between $\mu_{1}<t \leq \mu_{2}$, all inventory (retroactively) is charged a holding cost of $h_{2}$ per unit per time period; etc. Since the same holding cost will be applied to all units in the cycle, we only need to determine the total inventory level for the entire order cycle:

$$
q=\int_{0}^{t_{1}} I(t) d t
$$

Therefore, holding cost is

$$
H C=h_{i} \int_{0}^{t_{1}} I(t) d t=h_{i} D\left[\frac{t_{1}^{2}}{2}-\frac{\lambda t_{1}^{3}}{3}+\frac{\alpha \beta t_{1}^{\beta+1}}{(1+\beta)(\beta+2)}+\frac{\alpha \lambda t_{1}^{\beta+3}}{(1+\beta)(\beta+3)}\right]
$$

where $h$ is the corresponding value of $h=h_{i}$ for $\mu_{i-1}<t \leq \mu_{i}$. Thus, the average total cost $A T C_{1}\left(t_{1}\right)$ of inventory cycle is

$$
\begin{aligned}
A T C_{1}\left(t_{1}\right) & =\left[O C+H C_{1}+D C+S C+O P C\right] / T \\
A T C_{1}\left(t_{1}\right) & =\frac{D}{T}\left[h_{i}\left[\frac{t_{1}^{2}}{2}-\frac{\lambda t_{1}^{3}}{3}+\frac{\alpha \beta t_{1}^{\beta+1}}{(1+\beta)(\beta+2)}+\frac{\alpha \lambda t_{1}^{\beta+3}}{(1+\beta)(\beta+3)}\right]+\frac{c_{2} T}{D}\right. \\
& +c_{1} \alpha\left[\frac{t_{1}^{(1+\beta)}}{(1+\beta)}-\frac{\lambda t_{1}^{(2+\beta)}}{(2+\beta)}\right]+\frac{c_{3}}{\delta}\left[\frac{\left(1-e^{-\delta\left(T-t_{1}\right)}\right)}{\delta}-\left(T-t_{1}\right) e^{-\delta\left(T-t_{1}\right)}\right] \\
& \left.+c_{4} D\left[\left(T-t_{1}\right)-\frac{\left(1-e^{-\delta\left(T-t_{1}\right)}\right)}{\delta}\right]\right]
\end{aligned}
$$

In the first scenario, the objective is to determine the optimal values of shortage point $t_{1}$ in order to minimize the average total cost $A T C_{1}\left(t_{1}\right)$ per unit time. The optimal solutions $t_{1}^{*}$ need to satisfy the following equation.

$$
\frac{d A T C_{1}\left(t_{1}\right)}{d t_{1}}=\frac{D}{T} f_{1}\left(t_{1}\right)=0
$$

where

$$
f_{1}\left(t_{1}\right)=h_{i}\left[t_{1}-\lambda t_{1}^{2}+\frac{\alpha \beta t_{1}^{\beta+1}}{(1+\beta)}+\frac{\alpha \lambda t_{1}^{\beta+2}}{(1+\beta)}\right]+c_{1} \alpha\left[t_{1}^{\beta}-\lambda t_{1}^{\beta+1}\right]-\frac{\left(c_{4} \delta-c_{3} e^{-\delta\left(T-t_{1}\right)}\right)}{\delta},
$$




$$
-\left(T-t_{1}\right) c_{3} e^{-\delta\left(T-t_{1}\right)}-\frac{\left(c_{3}-\delta c_{4}\right) e^{-\delta\left(T-t_{1}\right)}}{\delta} .
$$

Theorem 1 If $1>\delta T, 1>>\lambda \geq 0$ and $\beta>1$ then the solutions to Eq. (15) not only exists but also is unique (i.e., the optimal values $t_{1}^{*}$ is uniquely determined).

Proof: From (15), it is easily verified that, when $\delta T<1$ and $1>>\lambda \geq 0 \lim _{t_{1} \rightarrow 0} f_{1}\left(t_{1}\right)<0$ and $\lim _{t_{1} \rightarrow T} f_{1}\left(t_{1}\right)>0$. Furthermore, taking first derivative of $f_{1}\left(t_{1}\right)$ with respect to $t_{1} \in(0, T)$, we get $d f_{1}\left(t_{1}\right) / d t_{1}>0$. So, $f_{1}\left(t_{1}\right)$ is a strictly increasing function of $t_{1} \in(0, T)$. It implies that the $(15)$ is verified at $t_{1}=t_{1}^{*}$, with $0<t_{1}^{*}<T$, which is the unique root of $f_{1}\left(t_{1}\right)=0$. This completes the proof.

Theorem 2 If $1>\delta T, 1>>\lambda \geq 0$ and $\beta>1$ the average total cost per unit time $A T C_{1}\left(t_{1}\right)$ is convex and reaches its global minimum at point $t_{1}^{*}$.

Proof: From Eq. (15), if, $1>\delta T, 1>>\geq 0$ we have

$$
\left.\frac{d^{2} A T C_{1}\left(t_{1}\right)}{d t_{1}^{2}}\right|_{t_{1}=t_{1}^{*}}=\left.\frac{D}{T}\left[f_{1}^{\prime}\left(t_{1}\right)\right]\right|_{t_{1}=t_{1}^{*}}>0 \text {. It implies, } t_{1}^{*} \text { corresponds to the global minimum of convex }
$$

$A T C_{1}\left(t_{1}\right)$. This completes the proof.

In this scenario, by using $t_{1}^{*}$, we can obtain the optimal maximum inventory level and the minimum average total cost per unit time from Eq. (5) and Eq. (14), respectively (we denote these values by $I_{\max }$ and $A T C_{1}\left(t_{1}^{*}\right)$ ). Furthermore, we can also obtain the optimal order quantity (we denote it by $Q^{*}$ ) from Eq. (8).

\subsubsection{Scenario 2: Incremental Holding Cost}

In this scenario, the discrete incremental unit holding cost increases as the time in storage increases. In this situation, though, an incremental holding cost implies that the holding cost of each storage period is applied only to the units apprehended during that period. That is, if the positive inventory time length is $\mu_{1}$ or less, the unit holding cost is $h_{1}$ per time period; if the storage time-span is between $\mu_{1}<t_{1} \leq \mu_{2}$, the holding cost of $h_{1}$ is applied to the average inventory during the storage period from 0 to $\mu_{1}$ and $h_{2}$ is applied from $\mu_{1}$ to $t_{1}$; etc. Thus, we require evaluating the average inventory level for each storage phase within the order cycle (note, for the last storage period, $\mu_{i}$ is replaced with $t_{1}$ ):

$$
q_{i}=\frac{D}{\left(\mu_{i}-\mu_{i-1}\right)} \int_{\mu_{i-1}}^{\mu_{i}} D\left[\left(t_{1}-t\right)-\lambda\left(\frac{t_{1}^{2}}{2}-\frac{t^{2}}{2}\right)+\frac{\alpha}{\beta+1}\left(t_{1}^{\beta+1}-t^{\beta+1}\right)\right]\left(1-\alpha t^{\beta}\right) d t .
$$

Therefore, holding cost per cycle is

$$
\begin{aligned}
H C_{2}= & \sum_{i=1}^{m} h_{i}\left(\mu_{i}-\mu_{i-1}\right) q_{i} \\
= & \sum_{i=1}^{m} h_{i} D\left[\left(\mu_{i}-\mu_{i-1}\right)\left(t_{1}-\frac{\lambda t_{1}^{2}}{2}+\frac{\alpha t_{1}^{\beta+1}}{(\beta+1)}\right)-\frac{\alpha\left(\mu_{i}^{\beta+1}-\mu_{i-1}^{\beta+1}\right)}{(\beta+1)}\left(t_{1}-\frac{\lambda t_{1}^{2}}{2}\right)\right. \\
& \left.+\frac{\alpha \beta\left(\mu_{i}^{\beta+2}-\mu_{i-1}^{\beta+2}\right)}{(\beta+1)(\beta+2)}-\frac{\left(\mu_{i}^{2}-\mu_{i-1}^{2}\right)}{2}+\frac{\lambda\left(\mu_{i}^{3}-\mu_{i-1}^{3}\right)}{6}-\frac{\alpha \lambda\left(\mu_{i}^{3}-\mu_{i-1}^{3}\right)}{2(\beta+3)}\right] .
\end{aligned}
$$


Thus, the average total cost $A T C_{2}\left(t_{1}\right)$ per unit time of inventory cycle is

$$
\begin{aligned}
A T C_{2}\left(t_{1}\right)=[ & \left.O C+H C_{2}+D C+S C+O P C\right] / T \\
A C T_{2}\left(t_{1}\right)= & \frac{1}{T}\left[\sum _ { i = 1 } ^ { m } h _ { i } \left[\left(\mu_{i}-\mu_{i-1}\right)\left(t_{1}-\frac{\lambda t_{1}^{2}}{2}+\frac{\alpha t_{1}^{\beta+1}}{(\beta+1)}\right)\right.\right. \\
& -\frac{\alpha\left(\mu_{i}^{\beta+1}-\mu_{i-1}^{\beta+1}\right)}{(\beta+1)}\left(t_{1}-\frac{\lambda t_{1}^{2}}{2}\right)+\frac{\alpha \beta\left(\mu_{i}^{\beta+2}-\mu_{i-1}^{\beta+2}\right)}{(\beta+1)(\beta+2)}-\frac{\left(\mu_{i}^{2}-\mu_{i-1}^{2}\right)}{2} \\
& \left.+\frac{\lambda\left(\mu_{i}^{3}-\mu_{i-1}^{3}\right)}{6}-\frac{\alpha \lambda\left(\mu_{i}^{3}-\mu_{i-1}^{3}\right)}{2(\beta+3)}\right]+\frac{c_{2} T}{D}+c_{1} \alpha\left[\frac{t_{1}^{(1+\beta)}}{(1+\beta)}-\frac{\lambda t_{1}^{(2+\beta)}}{(2+\beta)}\right] \\
& +\frac{c_{3}}{\delta}\left[\frac{\left(1-e^{-\delta\left(T-t_{1}\right)}\right)}{\delta}-\left(T-t_{1}\right) e^{-\delta\left(T-t_{1}\right)}\right]+c_{4} D\left[\left(T-t_{1}\right)-\frac{\left(1-e^{-\delta\left(T-t_{1}\right)}\right)}{\delta}\right] .
\end{aligned}
$$

In this scenario, the objective is to determine the optimal values of shortage point $t_{1}$ in order to minimize the average total cost $A T C_{2}\left(t_{1}\right)$ per unit time. The optimal solutions $t_{1}^{*}$ need to satisfy the following equation.

$$
\frac{d A T C_{2}\left(t_{1}\right)}{d t_{1}}=\frac{D}{T} f_{2}\left(t_{1}\right)=0
$$

where

$$
\begin{aligned}
f_{2}\left(t_{1}\right) & =\sum_{i=1}^{e} h_{i}\left[\left(1-\lambda t_{1}+\alpha t_{1}^{\beta}\right)\left(\mu_{i}-\mu_{i-1}\right)-\frac{\alpha\left(1-\lambda t_{1}\right)\left(\mu_{i}^{\beta+1}-\mu_{i-1}^{\beta+1}\right)}{(\beta+1)}\right] \\
& +c_{1} \alpha\left[t_{1}^{\beta}-\lambda t_{1}^{\beta+1}\right]-\frac{\left(c_{4} \delta-c_{3} e^{-\delta\left(T-t_{1}\right)}\right)}{\delta}-\left(T-t_{1}\right) c_{3} e^{-\delta\left(T-t_{1}\right)}-\frac{\left(c_{3}-\delta c_{4}\right) e^{-\delta\left(T-t_{1}\right)}}{\delta}
\end{aligned}
$$

Theorem 3 If $\sum_{i=1}^{e} h_{i}\left(\mu_{i}-\mu_{i-1}\right)<\sum_{i=1}^{e} \frac{h_{i} \alpha\left(\mu_{i}^{\beta+1}-\mu_{i-1}^{\beta+1}\right)}{(\beta+1)}+c_{4}\left(1-e^{-\delta T}\right)+c_{3} T e^{-\delta T}$ and $1>>\lambda>0$, then the solutions to Eq. (19) not only exists but also is unique (i.e., the optimal values $t_{1}^{*}$ is uniquely determined).

Proof: From Eq. (19), it is easily verified that, when $\sum_{i=1}^{e} h_{i}\left(\mu_{i}-\mu_{i-1}\right)<\sum_{i=1}^{e} \frac{h_{i} \alpha\left(\mu_{i}^{\beta+1}-\mu_{i-1}^{\beta+1}\right)}{(\beta+1)}+c_{4}\left(1-e^{-\delta T}\right)+c_{3} T e^{-\delta T}$ and $1>>\lambda>0 \lim _{t_{1} \rightarrow 0} f_{2}\left(t_{1}\right)<0$ and $\lim _{t_{1} \rightarrow T} f_{2}\left(t_{1}\right)>0$. Furthermore, taking first derivative of $f_{2}\left(t_{1}\right)$ with respect to $t_{1} \in(0, T)$, we get $d f_{2}\left(t_{1}\right) / d t_{1}>0$. So, $f_{2}\left(t_{1}\right)$ is a strictly increasing function of $t_{1} \in(0, T)$. It implies that the (19) is verified at $t_{1}=t_{1}^{*}$, with $0<t_{1}^{*}<T$, which is the unique root of $f_{2}\left(t_{1}\right)=0$. This completes the proof.

Theorem 4 If $\sum_{i=1}^{e} h_{i}\left(\mu_{i}-\mu_{i-1}\right)<\sum_{i=1}^{e} \frac{h_{i} \alpha\left(\mu_{i}^{\beta+1}-\mu_{i-1}^{\beta+1}\right)}{(\beta+1)}+c_{4}\left(1-e^{-\delta T}\right)+c_{3} T e^{-\delta T}$ and $1>>\lambda>0$, the average total cost per unit time $A_{T C}\left(t_{1}\right)$ is convex and reaches its global minimum at pointt $t_{1}^{*}$. 
Proof: From Eq. (19), if $\sum_{i=1}^{e} h_{i}\left(\mu_{i}-\mu_{i-1}\right)<\sum_{i=1}^{e} \frac{h_{i} \alpha\left(\mu_{i}^{\beta+1}-\mu_{i-1}^{\beta+1}\right)}{(\beta+1)}+c_{4}\left(1-e^{-\delta T}\right)+c_{3} T e^{-\delta T}$ and $1>>>0$ we have $\left.\frac{d^{2} A T C_{2}\left(t_{1}\right)}{d t_{1}^{2}}\right|_{t_{1}=t_{1}^{*}}=\left.\frac{D}{T}\left[f_{2}^{\prime}\left(t_{1}\right)\right]\right|_{t_{1}=t_{1}^{*}}>0$. It implies, $t_{1}^{*}$ corresponds to the global minimum of convex $A T C_{2}\left(t_{1}\right)$. This completes the proof. In this scenario, by using $t_{1}^{*}$, we can obtain the optimal maximum inventory level and the minimum average total cost per unit time $A T C_{2}\left(t_{1}^{*}\right)$ from (5) and (19), respectively. Furthermore, we can also obtain the optimal order quantity from (8).

\section{Numerical Examples}

As an illustration of both scenarios of developed model, a numerical example is presented for a single product. To perform the numerical analysis, data have been taken randomly from literatures in appropriate units.

Example 1: We consider an inventory system which verifies the described assumptions above. The input data of parameters are taken randomly as $T=4, a=0.4, b=2, \alpha=0.8, h_{1}=0.4, h_{2}=0.5, h_{3}=0.6$ $\beta=2, \mu_{0}=0, \mu_{1}=1, \mu_{2}=2, \mu_{3}=t_{1} d=10, c_{1}=3, c_{2}=1, c_{3}=3, R=2, H=0.4$ and $c_{4}=2$.

By using MATHEMATICA 8.0, the global minimum Average Total Cost per unit time $A T C_{i}\left(t_{1}\right)$, $i=1,2$ along with the optimal value of $t_{1}^{*}$ is calculated for each the proposed $\mathrm{i}$-th scenario. The Optimal Order Quantity $\left(Q^{*}\right)$ is also calculated in each scenario. The summary of crucial values for each scenario is given below.

\section{Table 1}

Summary of model's optimal values in i-th scenario

\begin{tabular}{llll}
\hline No. of scenario & $t_{1}^{*}$ & $Q^{*}$ & $A T C_{i}\left(t_{1}^{*}\right)$ \\
\hline 1 & 1.543017 & 115.4670 & 344.737 \\
2 & 1.584176 & 116.259 & 342.062 \\
\hline
\end{tabular}

Observations: One can make following remarks.

i.The Optimal Average Total Cost per unit time is greater in the scenario 1.

ii. The Optimal Order Quantity has maximum value in the scenario 2.

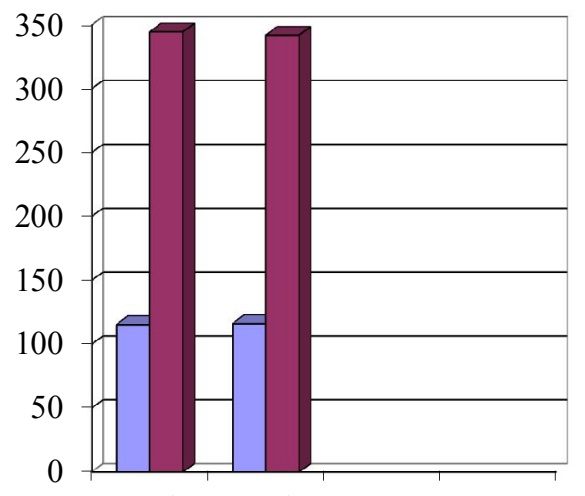

ScenarioScenario 2

Fig. 2. Inventory model optimal values for each scenario 


\section{Sensitivity Analysis}

In this section, the effects of studying the changes in the optimal value of Average Total Cost per unit time, the optimal shortage point and the optimal value of Order Quantity per cycle of each scenario with respect to changes in some model parameters are discussed. The sensitivity analysis in each scenario is performed by changing the value of each of the parameters by $\pm 5 \%$ and $\pm 10 \%$, taking one parameter at a time and keeping the remaining parameters unchanged. Example 1 is used in each scenario.

\subsection{Sensitivity Analysis for Scenario 1}

To discuss the effect of changes of model parameters $T, h_{1}, \alpha, \beta, \lambda, c_{1}, c_{3}, c_{4}$ and $\delta$ on the optimal value of the average total $\operatorname{cost}\left(A T C_{1}\left(t_{1}^{*}\right)=344.737\right)$, the shortage time point $\left(t_{1}^{*}=1.543017\right)$ and the value of Order Quantity per cycle $\left(Q^{*}=115.4670\right)$ for scenario 1 , the different values of these parameter according to $\pm 5 \%$ and $\pm 10 \%$ change in each have taken and its effect on $T A C_{1}\left(t_{1}^{*}\right), t_{1}^{*}$ and $Q^{*}$ are presented in the following Table 2.

Table 2

Sensitivity Analysis for Scenario 1

\begin{tabular}{|c|c|c|c|c|c|c|}
\hline \multirow[b]{2}{*}{ Parameters } & \multirow[b]{2}{*}{$t_{1}^{*}$} & \multirow{2}{*}{$Q^{*}$} & \multirow{2}{*}{$A T C_{1}\left(t_{1}^{*}\right)$} & \multicolumn{3}{|c|}{$\%$ change in the values of } \\
\hline & & & & $t_{1}^{*}$ & $Q^{*}$ & $A C T_{1}\left(t_{1}^{*}\right)$ \\
\hline \multirow{4}{*}{$T=4$} & 1.619650 & 120.013 & 337.220 & +4.97 & +3.93 & -2.18 \\
\hline & 1.582259 & 117.837 & 341.002 & +2.54 & +2.05 & -1.08 \\
\hline & 1.501826 & 112.879 & 348.373 & -2.67 & -2.26 & +1.05 \\
\hline & 1.458579 & 110.048 & 351.851 & -5.47 & -4.69 & +2.06 \\
\hline \multirow{4}{*}{$h_{1}=0.4$} & 1.528986 & 115.283 & 345.823 & -0.91 & -0.16 & +0.31 \\
\hline & 1.535944 & 115.334 & 345.285 & -0.45 & -0.11 & +0.16 \\
\hline & 1.550208 & 115.604 & 344.179 & +0.46 & +0.11 & -0.16 \\
\hline & 1.557521 & 115.743 & 343.610 & +0.94 & +0.24 & -0.32 \\
\hline \multirow{4}{*}{$\alpha=0.8$} & 1.487130 & 115.309 & 349.062 & -3.62 & -0.14 & +1.25 \\
\hline & 1.514258 & 115.392 & 346.973 & -1.86 & -0.06 & +0.65 \\
\hline & 1.573582 & 115.533 & 342.334 & +1.98 & +0.06 & -0.69 \\
\hline & 1.606155 & 115.588 & 339.745 & +4.09 & +0.14 & -1.44 \\
\hline \multirow{4}{*}{$\beta=2$} & 1.493807 & 114.694 & 348.099 & -3.18 & -0.67 & +0.97 \\
\hline & 1.577331 & 115.069 & 346.501 & -1.66 & -0.34 & +0.51 \\
\hline & 1.571146 & 115.890 & 342.781 & +1.82 & +0.37 & -0.57 \\
\hline & 1.602041 & 116.338 & 340.605 & +3.82 & +0.75 & -1.19 \\
\hline \multirow{4}{*}{$\lambda=0.1$} & 1.552731 & 115.531 & 343.997 & +0.63 & +0.05 & -0.21 \\
\hline & 1.547837 & 115.499 & 344.370 & +0.31 & +0.03 & -0.10 \\
\hline & 1.538269 & 115.437 & 345.097 & -0.31 & -0.02 & +0.10 \\
\hline & 1.533590 & 115.407 & 345.452 & -0.62 & -0.05 & +0.21 \\
\hline \multirow{4}{*}{$c_{1}=3$} & 1.494772 & 114.571 & 348.519 & -3.13 & -0.77 & +1.09 \\
\hline & 1.518356 & 115.005 & 346.679 & -1.59 & -0.40 & +0.56 \\
\hline & 1.568832 & 115.962 & 342.682 & +1.67 & +0.42 & -0.59 \\
\hline & 1.595885 & 116.489 & 340.505 & +3.43 & +0.88 & -1.22 \\
\hline \multirow{4}{*}{$c_{4}=2$} & 1.547561 & 115.553 & 311.002 & +0.29 & +0.07 & -9.78 \\
\hline & 1.545253 & 115.510 & 327.870 & +0.15 & +0.03 & -4.89 \\
\hline & 1.540735 & 115.424 & 361.602 & -0.15 & -0.03 & +4.89 \\
\hline & 1.538447 & 115.381 & 378.467 & -0.30 & -0.07 & +9.78 \\
\hline \multirow{4}{*}{$c_{3}=3$} & 1.601166 & 116.594 & 407.422 & +3.77 & +0.98 & +18.18 \\
\hline & 1.572582 & 116.034 & 376.160 & +1.92 & +0.49 & +9.11 \\
\hline & 1.512403 & 114.895 & 313.154 & -1.98 & -0.49 & -9.16 \\
\hline & 1.480661 & 114.316 & 281.416 & -4.04 & -0.99 & -18.37 \\
\hline \multirow{4}{*}{$\delta=0.1$} & 1.532175 & 106.942 & 269.351 & -0.70 & -7.38 & -21.87 \\
\hline & 1.537597 & 111.009 & 303.841 & -0.35 & -3.86 & -11.86 \\
\hline & 1.547597 & 120.179 & 394.314 & +0.30 & +4.08 & +14.38 \\
\hline & 1.553851 & 125.179 & 452.195 & +0.70 & +8.41 & +31.17 \\
\hline
\end{tabular}


Observations: From Table 2 the following observations can be made as:

1. $A T C_{1}\left(t_{1}^{*}\right)$ increases with increase in the values of model parameters $h_{1}, \alpha, \beta, c_{1}$ and $c_{3}$ while $A T C_{1}\left(t_{1}^{*}\right)$ decreases with increase in the value of $T, \lambda, c_{4}$ and $\delta . A T C_{1}\left(t_{1}^{*}\right)$ is highly sensitive to changes in $T, c_{3}, c_{4}$ and $\delta$. It is less sensitive to changes in $\alpha, \beta$ and $c_{1}$; and very less sensitive to change in $h_{1}$ and $\lambda$;

2. $A T C_{1}\left(t_{1}^{*}\right)$ decreases with decrease in the values of model parameters $h_{1}, \alpha, \beta, c_{1}$ and $c_{3}$ while $A T C_{1}\left(t_{1}^{*}\right)$ increases with decrease in the value of $T, \lambda, c_{4}$ and $\delta . A T C_{1}\left(t_{1}^{*}\right)$ is highly sensitive to changes in $T, c_{3}, c_{4}$ and $\delta$. It is less sensitive to changes in $\alpha, \beta$ and $c_{1}$; and very less sensitive to change in $h_{1}$ and $\lambda$;
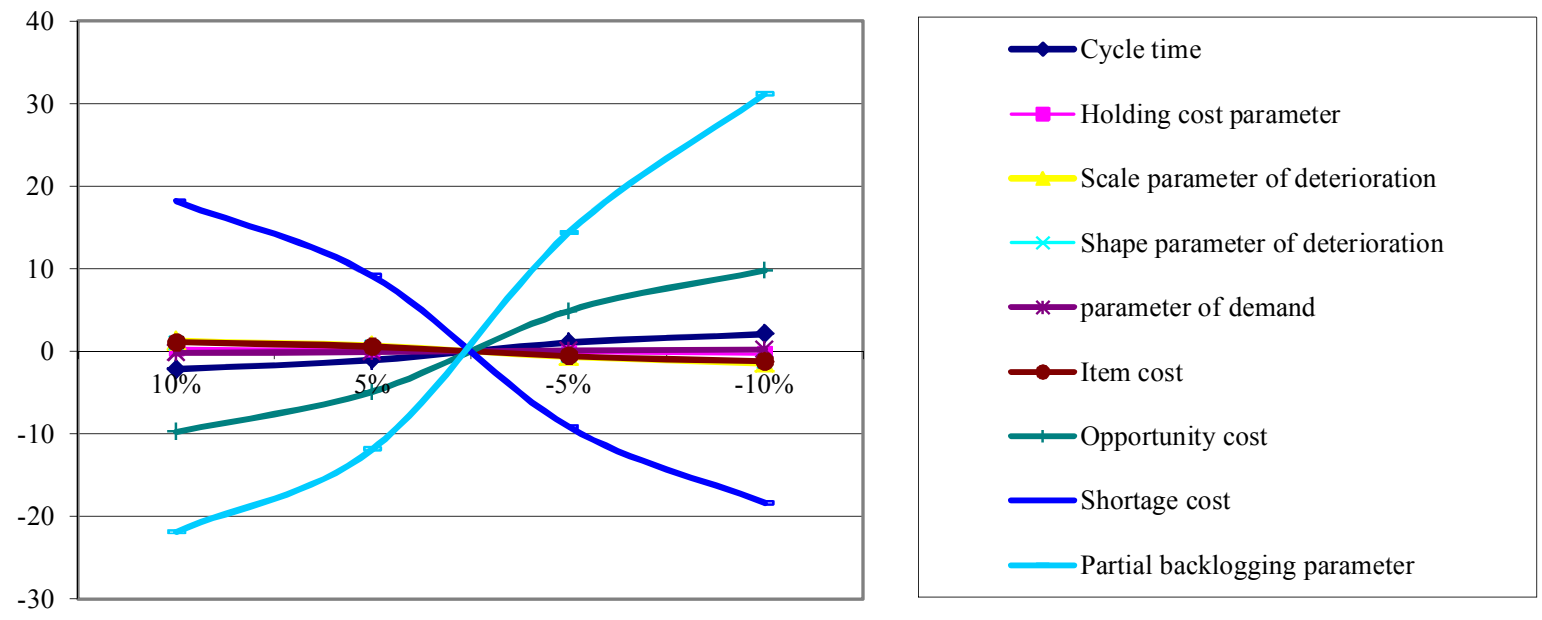

Fig. 3. Behavior of optimal average total cost per unit time in scenario 1
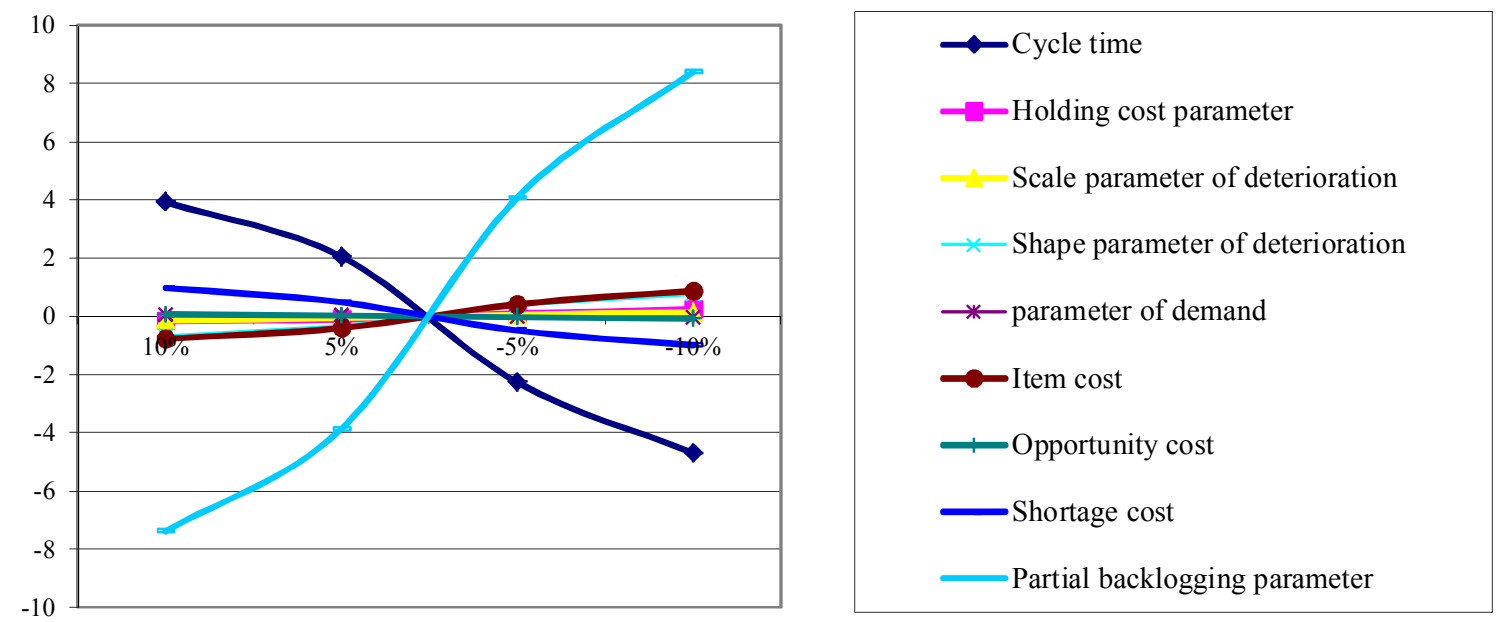

Fig. 4. Behavior of optimal ordering quantity in scenario 1

3. $Q^{*}$ increases with increase in the values of model parameters $T, \lambda, c_{3}$ and $c_{4}$ while $Q^{*}$ decreases with increase in the value of $h_{1}, \alpha, \beta, c_{1}$ and $\delta . Q^{*}$ is highly sensitive to changes in $T$ and $\delta$. It is less sensitive to changes in $h_{1}, \beta, c_{1}$ and $c_{3}$; and very less sensitive to change in $\alpha, \lambda$ and $c_{4}$; 
4. $Q^{*}$ decreases with decrease in the values of model parameters $T, \lambda, c_{3}$ and $c_{4}$ while $Q^{*}$ increases with decrease in the value of $h_{1}, \alpha, \beta, c_{1}$ and $\delta$. $Q^{*}$ is highly sensitive to changes in $T$ and $\delta$. It is less sensitive to changes in $h_{1}, \beta, c_{1}$ and $c_{3}$; and very less sensitive to change in $\alpha, \lambda$ and $c_{4}$.

\subsection{Sensitivity Analysis for Scenario 2}

To discuss the effect of changes of model parameters $T, h_{1}, \alpha, \beta, \lambda, c_{1}, c_{3}, c_{4}$ and $\delta$ on the optimal value of the average total $\operatorname{cost}\left(A T C_{2}\left(t_{1}^{*}\right)=342.062\right)$, the shortage time point $\left(t_{1}^{*}=1.584176\right)$ and the value of Order Quantity per cycle $\left(Q^{*}=116.259\right)$ for scenario 2 , the different values of these parameter according to $\pm 5 \%$ and $\pm 10 \%$ change in each have taken and its effect on $T A C_{2}\left(t_{1}^{*}\right), t_{1}^{*}$ and $Q^{*}$ are presented in the following Table 3.

Table 3

Sensitivity Analysis for Scenario 2

\begin{tabular}{|c|c|c|c|c|c|c|}
\hline \multirow{2}{*}{ Parameters } & \multirow{2}{*}{$t_{1}^{*}$} & \multirow{2}{*}{$Q^{*}$} & \multirow{2}{*}{$A T C_{2}\left(t_{1}^{*}\right)$} & \multicolumn{3}{|c|}{$\%$ change in the values of } \\
\hline & & & & $t_{1}^{*}$ & $Q^{*}$ & $A C T_{2}\left(t_{1}^{*}\right)$ \\
\hline \multirow{4}{*}{$T=4$} & 1.669500 & 121.191 & 334.654 & +5.38 & +4.24 & -2.16 \\
\hline & 1.627751 & 118.817 & 338.377 & +2.75 & +2.20 & -1.07 \\
\hline & 1.538688 & 113.496 & 345.666 & -2.87 & -2.37 & +1.05 \\
\hline & 1.491191 & 110.504 & 349.133 & -5.87 & -4.95 & +2.07 \\
\hline \multirow{4}{*}{$h_{1}=0.4$} & 1.572252 & 116.027 & 343.028 & -0.75 & -0.19 & +0.28 \\
\hline & 1.578188 & 116.143 & 342.548 & -0.37 & -0.09 & +0.14 \\
\hline & 1.590217 & 116.378 & 341.571 & +0.38 & +0.10 & -0.14 \\
\hline & 1.596311 & 116.498 & 341.075 & +0.76 & +0.20 & -0.29 \\
\hline \multirow{4}{*}{$\alpha=0.8$} & 1.521925 & 116.011 & 346.880 & -3.93 & -0.21 & +1.41 \\
\hline & 1.552087 & 116.138 & 344.659 & -2.08 & -0.10 & +0.72 \\
\hline & 1.618405 & 116.373 & 339.366 & +2.16 & +0.09 & -0.79 \\
\hline & 1.655021 & 116.476 & 336.443 & +4.47 & +0.18 & -1.64 \\
\hline \multirow{4}{*}{$\beta=2$} & 1.527272 & 115.364 & 345.990 & -3.59 & -0.76 & +1.14 \\
\hline & 1.554366 & 115.797 & 344.132 & -1.88 & -0.39 & +0.60 \\
\hline & 1.617085 & 116.753 & 339.744 & +2.07 & +0.42 & -0.68 \\
\hline & 1.653559 & 117.279 & 337.135 & +4.38 & +0.88 & -1.44 \\
\hline \multirow{4}{*}{$\lambda=0.1$} & 1.595859 & 116.362 & 341.178 & +0.74 & +0.08 & -0.26 \\
\hline & 1.589962 & 116.310 & 341.625 & +0.36 & +0.04 & -0.13 \\
\hline & 1.578497 & 116.211 & 342.491 & -0.36 & -0.04 & +0.12 \\
\hline & 1.572921 & 116.164 & 342.911 & -0.71 & -0.08 & +0.24 \\
\hline \multirow{4}{*}{$c_{1}=3$} & 1.529091 & 115.205 & 346.347 & -3.47 & -0.90 & +1.25 \\
\hline & 1.555909 & 115.713 & 344.272 & -1.78 & -0.46 & +0.65 \\
\hline & 1.614026 & 116.850 & 339.704 & +1.88 & +0.50 & -0.69 \\
\hline & 1.645610 & 117.491 & 337.179 & +3.88 & +1.05 & -1.43 \\
\hline \multirow{4}{*}{$c_{4}=2$} & 1.589090 & 116.356 & 308.276 & +0.31 & +0.08 & -9.88 \\
\hline & 1.586636 & 116.308 & 325.170 & +0.15 & +0.04 & -4.93 \\
\hline & 1.581708 & 116.211 & 358.954 & -0.15 & -0.04 & +4.93 \\
\hline & 1.579230 & 116.763 & 375.844 & -0.31 & -0.08 & +9.87 \\
\hline \multirow{4}{*}{$c_{3}=3$} & 1.647231 & 117.524 & 404.041 & +3.98 & +1.08 & +18.12 \\
\hline & 1.616221 & 116.894 & 373.145 & +2.02 & +0.55 & +9.08 \\
\hline & 1.551025 & 115.619 & 310.795 & -2.09 & -0.55 & -9.14 \\
\hline & 1.516686 & 114.974 & 279.847 & -4.26 & -1.10 & -18.33 \\
\hline \multirow{4}{*}{$\delta=0.1$} & 1.572687 & 107.747 & 267.054 & -0.72 & -7.32 & -21.92 \\
\hline & 1.578434 & 111.808 & 301.370 & -0.36 & -3.82 & -11.89 \\
\hline & 1.589913 & 121.162 & 390.622 & +0.36 & +4.22 & +14.19 \\
\hline & 1.595645 & 126.592 & 448.987 & +0.72 & +8.88 & +31.25 \\
\hline
\end{tabular}

Observations: From Table 3 the following observations can be made as; 
1. $A T C_{2}\left(t_{1}^{*}\right)$ increases with increase in the values of model parameters $h_{1}, \alpha, \beta, c_{1}$ and $c_{3}$ while $A T C_{2}\left(t_{1}^{*}\right)$ decreases with increase in the value of $T, \lambda, c_{4}$ and $\delta . A T C_{2}\left(t_{1}^{*}\right)$ is highly sensitive to changes in $T, c_{3}, c_{4}$ and $\delta$. It is less sensitive to changes in $\alpha, \beta$ and $c_{1}$; and very less sensitive to change in $h_{1}$ and $\lambda$.

2. $A T C_{2}\left(t_{1}^{*}\right)$ decreases with decrease in the values of model parameters $h_{1}, \alpha, \beta, c_{1}$ and $c_{3}$ while $A T C_{2}\left(t_{1}^{*}\right)$ increases with decrease in the value of $T, \lambda, c_{4}$ and $\delta . A T C_{2}\left(t_{1}^{*}\right)$ is highly sensitive to changes in $T, c_{3}, c_{4}$ and $\delta$. It is less sensitive to changes in $\alpha, \beta$ and $c_{1}$; and very less sensitive to change in $h_{1}$ and $\lambda$.
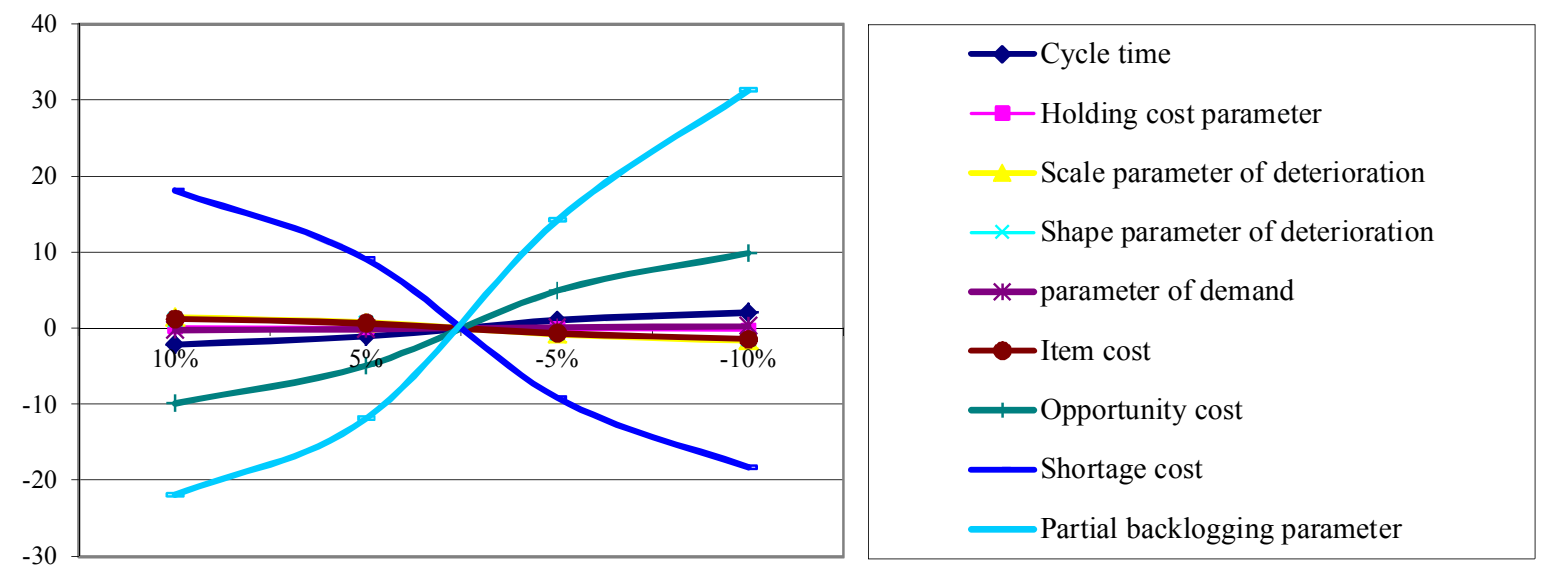

Fig. 5. Behavior of optimal average total cost per unit time in scenario 2
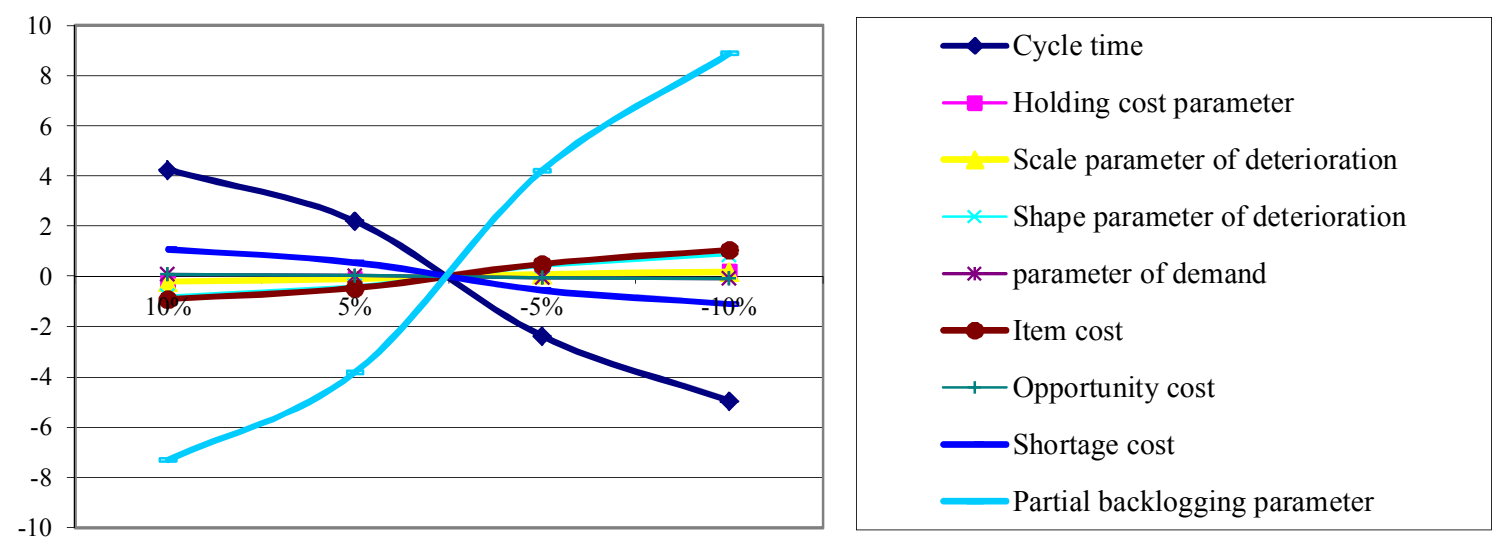

Fig. 6. Behavior of optimal ordering quantity in scenario 2

3. $Q^{*}$ increases with increase in the values of model parameters $T, \lambda, c_{3}$ and $c_{4}$ while $Q^{*}$ decreases with increase in the value of $h_{1}, \alpha, \beta, c_{1}$ and $\delta . Q^{*}$ is highly sensitive to changes in $T$ and $\delta$. It is less sensitive to changes in $h_{1}, \beta, c_{1}$ and $c_{3}$; and very less sensitive to change in $\alpha, \lambda$ and $c_{4}$.

4. $Q^{*}$ decreases with decrease in the values of model parameters $T, \lambda, c_{3}$ and $c_{4}$ while $Q^{*}$ increases with decrease in the value of $h_{1}, \alpha, \beta, c_{1}$ and $\delta . Q^{*}$ is highly sensitive to changes in $T$ and $\delta$. It is less sensitive to changes in $h_{1}, \beta, c_{1}$ and $c_{3}$; and very less sensitive to change in $\alpha, \lambda$ and $c_{4}$. 


\section{Conclusions}

In this model, we have studied an inventory model in which the inventory is depleted not only by declining pattern of demand but also by Weibull distributed deterioration where holding cost per unit time is considered a discretely variable. Shortages are allowed and partially backlogged. Conditions for existence and uniqueness of the optimal solution have been provided. Therefore, the proposed model can be used widely in inventory-control of certain deteriorating items such as food items, electronic components, and fashionable commodities, and others. Moreover, the advantage of the proposed inventory model is illustrated with example. This study highlights that the optimal average total cost per unit time is high when holding cost per unit per unit time is considered as retroactively to all previous periods of storing and optimal value of ordered quantity is less. On the other hand, the optimal average total cost per unit time is less when holding cost per unit per unit time is considered as incremental to periods of storing and optimal value of ordered quantity is high. In future, this paper may be extended with stochastic demand and permissible delay of payment.

\section{Acknowledgment}

The author would like to sincerely thank the anonymous referees whose comments improved the earlier version of this paper.

\section{References}

Abad, P.L. (2000). Optimal lot size for a perishable good under conditions of finite production and partial backordering and lost sale. Computers \& Industrial Engineering, 38, 457-465.

Aggarwal, S.P. (1978). A note on an order-level model for a system with constant rate of deterioration. Opsearch, 15, 184-187.

Alfares, H.K. (2007). Inventory model with stock-level dependent demand rate and variable holding cost. International Journal of Production Economics, 108, 12, 259-265.

Bhunia, A. K. \& Shaikh, A.A. (2011). A deterministic model for deteriorating items with displayed inventory level dependent demand rate incorporating marketing decisions with transportation cost. International Journal of Industrial Engineering Computations, 2, 547-562.

Chang, H.J. \& Dye, C.Y. (1999). An EOQ model for deteriorating items with time varying demand and partial backlogging. Journal of the Operational Research Society, 50, 1176-1182.

Dye, C.Y., Ouyang, L.Y., \& Hsieh, T.P. (2007). Inventory and pricing strategies for deteriorating items with shortages: A discounted cash flow approach. Computers and industrial Engineering, 52, 29-40.

Ferguson, M., Hayaraman, V. \& Souza, G.C. (2007). Note: An application of the EOQ model with nonlinear holding cost to inventory management of perishables. European Journal of Operational Research, 180, 1, 485-490.

Hollier, R.H. \& Mak, K.L. (1983). Inventory replenishment policies for deteriorating items in a declining market. International Journal of Production Research, 21, 813-826.

Hou, K.L. (2006).An inventory model for deteriorating items with stock-dependent consumption rate and shortages under inflation and time discounting. European Journal of Operational Research, $168,463-474$.

Hung, K.C. (2011).An inventory model with generalized type demand, deterioration and backorder rates. European Journal of Operational Research, 208, 239- 242.

Jaggi, C.K., Aggarwal, K.K., \& Goel, S.K. (2006). Optimal order policy for deteriorating items With inflation induced demand. International Journal of Production Economics, 103, 707-714.

Jaggi, C.K., Goel, S.K., \& Mittal, M. (2011). Economic order quantity model for deteriorating items with imperfect quality and permissible delay on payment. International Journal of Industrial Engineering Computations, 2(2), 237-248. 
Khanra, S. Ghosh, S.K., \& Chaudhuri, K.S. (2011). An EOQ model for a deteriorating item with timedependent quadratic demand under permissible delay in payment. Applied Mathematics and Computation, 218, 1- 9.

Liao, J.J., \& Huang, K.N. (2010).Deterministic inventory model for deteriorating items with trade credit financing and capacity constraints. Computers and Industrial Engineering, 59, 611-618.

Lin, J. (2012). A demand independent inventory control. Yugoslav Journal of Operations Research, 22, $1-7$.

Mishra, V.K. \& Singh, L.S. (2011). Deteriorating inventory model for time dependent demand and holding cost with partial backlogging. International Journal of Management Science and Engineering Management, 6, 4, 267-271.

Park, K.S. (1982). Inventory models with partial backorders. International Journal of Systems Science, $13,1313-1317$.

Papachristos, S. \& Skouri, K. (2000). An optimal replenishment policy for deteriorating items with time-varying demand and partial exponential type-backlogging. Operations Research Letters, 27, $175-184$.

Papachristos, S. \& Skouri, K. (2003). An inventory model with deteriorating items, quantity discount, pricing and time-dependent partial backlogging. International Journal of Production Economics, 83, 247-256.

Patra, S. K., Lenka, T. K., \& Ratha, P.C. (2010). An order level EOQ model for deteriorating items in a single warehouse system with price dependent demand in non-linear form. International Journal of Computational and Applied Mathematics, 5(3), 277-288.

Sana, S.S. (2010). Optimal selling price and lot size with time varying deterioration and partial backlogging. Applied Mathematics and Computation, 217, 185- 194.

Skouri, K., Konstantaras, I., Papachristos, S., \& Teng, J.T. (2011). Supply chain models for deteriorating products with ramp type demand rate under permissible delay in payments. Expert Systems with Applications, 38, 14861-14869.

Taleizadeh, A.A., Widyadana, G.A., Wee, H.M., \& Biabani, J. (2011). Multi products single machine economic production quantity model with multiple batch size. International Journal of Industrial Engineering Computations, 2(2), 213-224.

Taleizadeh, A.A., Cárdenas-Barrón, L.E., Biabani, J., \& Nikousokhan, R. (2012). Multi products single machine EPQ model with immediate rework process. International Journal of Industrial Engineering Computations, 3(2), 93-102.

Teng, J.T., Yang, H.L., \& Ouyang, L.Y. (2003). On an EOQ model for deteriorating items with timevarying demand and partial backlogging. Journal of Operational Research Society, 54 (4), 432436.

Teng, J.T., \& Yang, H.L. (2004). Deterministic economic order quantity models with partial backlogging when demand and cost are fluctuating with time. Journal of the Operational Research Society, 55 (5), 495-503.

Teng, J.T., Oyang, L.Y., \& Chen, L.H. (2007).A comparison between two pricing and lot-sizing models with partial backlogging and deteriorated items. International Journal of Production Economics, 105 (1), 190-203.

Tyagi, A.P., Pandey, R.K. \& Singh, S.R. (2012). Optimization of inventory model for decaying item with variable holding cost and power demand. Proceedings of National Conference on Trends \& Advances in Mechanical Engineering, ISBN: 978-93-5087-574-2, 774-781.

Tripathi, R.P. (2013). Inventory model with different demand rate and different holding cost. International Journal of Industrial Engineering Computations, 4, 437-446.

Weiss, H.J. (1982). Economic order quantity models with nonlinear holding costs. European Journal of Operational Research, 9, 56-60.

Wee, H.M. (1995). A deterministic lot-size inventory model for deteriorating items with shortages and a declining market. Computers \& Operations Research, 22, 345-356.

Wang, S.P. (2002). An inventory replenishment policy for deteriorating items with shortages and partial backlogging. Computers \& Operations Research, 29, 2043-2051. 
Yang, H.L. (2005).A comparison among various partial backlogging inventory lot-size models for deteriorating items on the basis of maximum profit. International Journal of Production Economics, 96 (1), 119-128.

Yang, H. L., Teng, J. T. \& Chern, M. S. (2010). An inventory model under inflation for deteriorating items with stock-dependent consumption rate and partial backlogging shortages. International Journal of Production Economics, 123, 8-19. 